\title{
Overview of Nutrition Care in Geriatrics and Orthogeriatrics
}

\author{
Ólöf G. Geirsdóttir, Karen Hertz, Julie Santy-Tomlinson, \\ Antony Johansen, and Jack J. Bell
}

\begin{abstract}
Engaging older adults, and all those who care for them, is pivotal to providing high-value nutrition care for older adults. Nurses and other interdisciplinary team members are essential to this process. The aim of this chapter is to provide an overview of the rationale and evidence for interdisciplinary and systematised nutrition care as an effective nutrition care approach for older adults with or at risk of malnutrition. This chapter also serves as a guide to detailed chapters
\end{abstract}

\footnotetext{
Ó. G. Geirsdóttir $(\bowtie)$

Faculty of Food Science and Nutrition, School of Health Science, University of Iceland, Reykjavík, Iceland

e-mail: ogg@hi.is

K. Hertz

Royal Stoke University Hospital, Stoke-on-Trent, UK

e-mail: karen.hertz@uhns.nhs.uk

\section{J. Santy-Tomlinson}

Orthopaedic Nursing, Odense University Hospitals/University of Southern Denmark,

Odense, Denmark

e-mail: juliesanty@tomlinson15.karoo.co.uk
}

\author{
A. Johansen \\ Trauma Unit, University Hospital of Wales, Cardiff, UK
}

National Hip Fracture Database, Royal College of Physicians, London, UK

e-mail: antony.johansen@wales.nhs.uk

J. J. Bell

Allied Health, The Prince Charles Hospital, Chermside, Queensland, Australia

School of Human Movement and Nutrition Sciences, The University of Queensland, St Lucia, QLD, Australia

e-mail: jack.bell@health.qld.gov.au

(C) The Author(s) 2021

Ó. G. Geirsdóttir, J. J. Bell (eds.), Interdisciplinary Nutritional Management and

Care for Older Adults, Perspectives in Nursing Management and Care for Older

Adults, https://doi.org/10.1007/978-3-030-63892-4_1 
across this book to provide focal points on different aspects of nutrition care that should be considered across primary prevention, acute care, rehabilitation, secondary prevention and community settings (Dreinhöfer et al., Injury 49(8):1393-1397, 2018).

\section{Keywords}

Fragility fracture $\cdot$ Malnutrition $\cdot$ Nutritional assessment $\cdot$ Nutrition care $\cdot$ Older Hip fracture $\cdot$ Sarcopenia $\cdot$ Nutrition care

\section{Learning Outcomes}

By the end of this chapter, you will be able to:

- Recognise the complexities of nutrition care for old people.

- Explain the rationale and benefit of shifting towards integrated, transdisciplinary nutrition care across healthcare and community settings.

- Apply key questions that will support timely, efficient and effective nutrition care for older persons across broad populations, conditions and settings.

\section{$1.1 \quad$ Defining Malnutrition}

Malnutrition broadly refers to deficiencies, excesses or imbalances in a person's intake of energy and/or nutrients. Undernutrition includes energy or macronutrient deficiencies (protein-energy malnutrition) and micronutrient deficiencies or insufficiencies, while overnutrition is routinely associated with overweight, obesity and diet-related noncommunicable diseases $[1,2]$. This book will present a focus on malnutrition as undernutrition.

There is no definitive or 'gold standard' screening or diagnostic criteria for malnutrition [3]. Despite the availability of several validated nutritional assessments, malnutrition is often under- or misdiagnosed, overlooked and undervalued in multimorbid older adults, such as those with a fragility hip fracture [4-7].

Malnutrition diagnosis requires a thorough assessment and single-point diagnostic measures are unreliable. For example, malnutrition may be recognised in a chronically malnourished patient with normal albumin levels, but it can also be present in an acutely unwell older adult despite a high body mass index (BMI) of $50 \mathrm{~kg} / \mathrm{m}^{2}$ [4]. Conversely, an older adult with reduced handgrip strength resulting from motor-neurone disease should not immediately be considered malnourished without further investigation.

Muscle strength and function diminish as part of the normal ageing process, so a centenarian presenting with limited muscle reserves should not automatically be given a diagnosis of malnutrition, until it has been established whether loss of muscle mass, strength and function is in part attributable to malnutrition, for example, related to anorexia of ageing. 


\subsection{Nutrition Care in Older Adults: A Complex and Necessary Challenge}

Malnutrition in older people is increasing in prevalence as the population ages [2, $8-10]$. The prevalence of undernutrition in older people living in the community is about one in five [11-13]. Within clinical settings, malnutrition prevalence rates routinely approach half of older adults, although prevalence estimates vary substantially depending on the population, the healthcare setting and methods used for assessment [14-18].

Poor nutritional status is well established as a negative prognostic indicator among older adults, leading to functional decline, lower quality of life and increases in complications, morbidity and mortality, lengths of stay, unplanned readmissions, institutionalisation and costs [19-25]. It is worth noting that malnutrition can more than double the risk of dying for older adults [26, 27].

A practical case example is an older community-dwelling person admitted with fragility hip fracture. Although the surgical intervention and fracture union may have been successful, extended length of stay, residential care placement and early mortality can all still arise with sarcopenia, functional decline and multiple pressure injuries, all of which are attributable to hospital-acquired malnutrition.

A further dimension to the implications of malnutrition is the societal consequence of ageing. The increasing burden on the working age population is captured in the Old-Age Dependency Ratio [28, 29], and this emphasises the importance of good nutrition throughout the lifespan. Implications include:

- Society will need older adults to be independent for much longer in the future.

- Survival into old age is not going to be enough; quality of life is more important to older adults than longevity.

- Demographic change is going to be extremely rapid, increasing pressure on health and social care services; society must start adapting and adopting measures immediately.

The challenge of providing nutrition care for ageing populations is multifactorial. Urgent attention is required globally so that older adults and healthcare providers can understand the continuum of nutrition care across the lifecycle. 'Healthy eating' and optimal nutrition health during pre-older adult years must provide the groundwork for healthy ageing, but we need to re-evaluate what 'healthy eating' looks like in older adults.

The onset of frailty and other conditions of old age requires us to consider changing the focus of nutrition care away from lifestyle advise and the prevention of obesity and towards prevention of functional loss and the maintenance of muscle mass, bone integrity and quality of life.

This may at first appear counter-intuitive, for example, prescribing supplements in an obese inpatient at risk of malnutrition after hip fracture or deprescribing a long-standing 'low-cholesterol diet' for someone admitted to a cardiac unit with underlying malnutrition [30, 31]. It may simply mean accepting the risk of 
aspiration in an older adult with end-stage Parkinson's disease and allowing them unrestricted food and fluids for the comfort, enjoyment and social interactions that mealtimes offer. When and where such shifts in the focus of nutrition care should occur will depend on age-related changes, comorbidities, sociocultural factors and, most importantly, what matters to the older adult.

\subsection{Malnutrition: A Truly Wicked Problem}

Malnutrition is multifactorial and underlying factors that can lead to malnutrition are many and varied. In some cases, malnutrition cannot be resolved, although attentive management may improve outcomes for older adults and the systems that care for them. There are no single 'silver bullet' solutions; this is one of many reasons why malnutrition is considered to meet the definition of a 'wicked' problem as initially described by Rittel and Webber (Table 1.1) [32,33].

\subsection{Building the Rationale for Integrated Nutrition Care}

It is important that healthcare providers are proactive in identifying individual causes, signs and symptoms of malnutrition. If identified early, malnutrition can be treated with individualised nutritional intervention plans which should be supported by effective systems and cohesive, integrated care processes [1]. While early recognition and treatment of malnutrition are recognised as beneficial for the health and wellbeing of the older person, nutritional diagnosis and a timely nutrition care can also reduce overall healthcare and community costs [34-36].

Table 1.1 Why malnutrition in older adults should be considered as a wicked problem [32, 33]

- Profession and scientific definitions and diagnostic criteria continually evolve over time

- Shared and overlapping boundaries between ageing, cachexia, frailty, obesity, sarcopenia and other conditions

- Unique individual presentations in ageing limit the usefulness of clinical algorithms and the accuracy of tools

- The diagnosis and related underlying problems cannot be routinely reduced to single-base variables

- The aetiology of malnutrition is multifactorial; underlying factors that can contribute to malnutrition are many and varied

- There are unfixed, iterative and adaptive solutions that require tailoring across settings

- There are no 'right' or 'wrong' solutions; and in many cases management, rather than resolution, may be appropriate

- There are no 'silver bullets' providing all the solutions

- Clinician actions are constrained by a lack of or contradictory evidence, resource limitations, the balance between food as a right to life and food as a medicine and older adult preferences and beliefs

- Intervention and outcome evaluations are routinely confounded by other factors

- Every older adult and setting should be considered essentially unique 


\begin{tabular}{|c|c|c|c|}
\hline Silos & Multidisciplinary & Interdisciplinary & Transdisciplinary \\
\hline $\begin{array}{l}\text { Working independently of } \\
\text { other disciplines } \\
\text { Ineffective or dis-integrated } \\
\text { communication and clinical } \\
\text { care } \\
\text { Guards professional } \\
\text { boundaries, knowledge and } \\
\text { skills }\end{array}$ & $\begin{array}{l}\text { Working in parallel or } \\
\text { sequentially with other } \\
\text { disciplines } \\
\text { Shared goals } \\
\text { Maintains disciplinary } \\
\text { boundaries }\end{array}$ & $\begin{array}{l}\text { Working together from } \\
\text { individual disciplinary } \\
\text { perspectives } \\
\text { Tendency to maintain } \\
\text { disciplinary boundaries } \\
\text { Common goal focus }\end{array}$ & $\begin{array}{l}\text { Working jointly together } \\
\text { Transcending disciplinary } \\
\text { boundaries } \\
\text { Sharing and integrating } \\
\text { knowledge, skills, } \\
\text { accountabilities } \\
\text { Focus together on solving real } \\
\text { world, complex problems }\end{array}$ \\
\hline
\end{tabular}

Fig. 1.1 Moving from silos to transdisciplinary care [41, 42]

The nature of nutrition care, and geriatric practice more generally, predicates a comprehensive approach delivered by multiple healthcare providers across the continuum of care [37, 38]. Appropriate nutrition care for older adults is not something that will occur organically, but requires cultivating towards integrated, transdisciplinary approaches to deliver efficient, effective and sustainable nutrition care across acute, rehabilitation and community settings [7, 27, 39, 40]. Multi-agency collaboration; integrated organisational and administrative structures; shared skills, tasks and goals across all relevant actors; collaborative leadership; and, most importantly, a focus on what matters to the older adult are all key components of transdisciplinary care. These are also the necessary ingredients to manage the wicked problem of malnutrition. Consequently, continual progression along the continuum from siloed, single-discipline approaches to transdisciplinary care (Fig. 1.1) is most likely to impact positively on nutrition care.

\subsection{Managing the Wicked Nutrition Problems with a SIMPLE Approach (or Other Tailored Models)}

The sheer volume of older adults with or at risk of malnutrition or other nutritionrelated diagnoses, combined with increasing health expenditure and competing demands for resources, have resulted in demand outstripping supply of individual access to nutrition specialists [22]. Internationally, there are several models available that support interdisciplinary healthcare teams to deliver timely and appropriate nutrition care, for example, the Systematised, Interdisciplinary Malnutrition Program for impLementation and Evaluation (SIMPLE), the More-2-Eat implementation programme targeting improving nutrition culture within hospitals and Malnutrition Universal Screening Tool (MUST) [27, 43, 44].

These models usually triage those screened into one of three groups: those 'not at risk' and appropriate for standard care, those who are at risk or malnourished who are appropriate for interdisciplinary or 'supportive' nutrition care and those who are likely to benefit from the intervention of a nutrition care specialist, or 'specialist nutrition care'. Specialised nutritional interventions tailored to individual requirements have demonstrated positive influence on outcomes in the acute and 
rehabilitation settings $[27,45,46]$. However, for many individuals across diverse geriatric care settings, reliance on 'specialist' nutrition care may not add additional benefit to the fundamental nutrition care that could and should be provided by the rest of the team as 'supportive' nutrition care. Specialised nutrition care may be delayed because of many diverse reasons, varying from inadequate availability of specialists, no weekend cover or clinical prioritisation requirements, and, in many locations, it may simply not be available because of either lack of funding or the availability of clinicians to fill advertised positions, particularly in rural and remote settings.

\subsubsection{Keep It SIMPLE When Appropriate}

While recognising that nutrition care in older adults is often complex, in a high proportion of cases and settings, supportive SIMPLE nutrition care is appropriate.

Figure 1.2 provides an illustrative summary of how healthcare professionals can contribute to systematised, interdisciplinary supportive nutrition care for individual older adults with, or at risk of, a nutrition-related diagnosis. This figure has been adapted from the SIMPLE model and is composition of key nutrition care models applied internationally [27, 43, 46-48]. This is further detailed in Bell et al. [7].

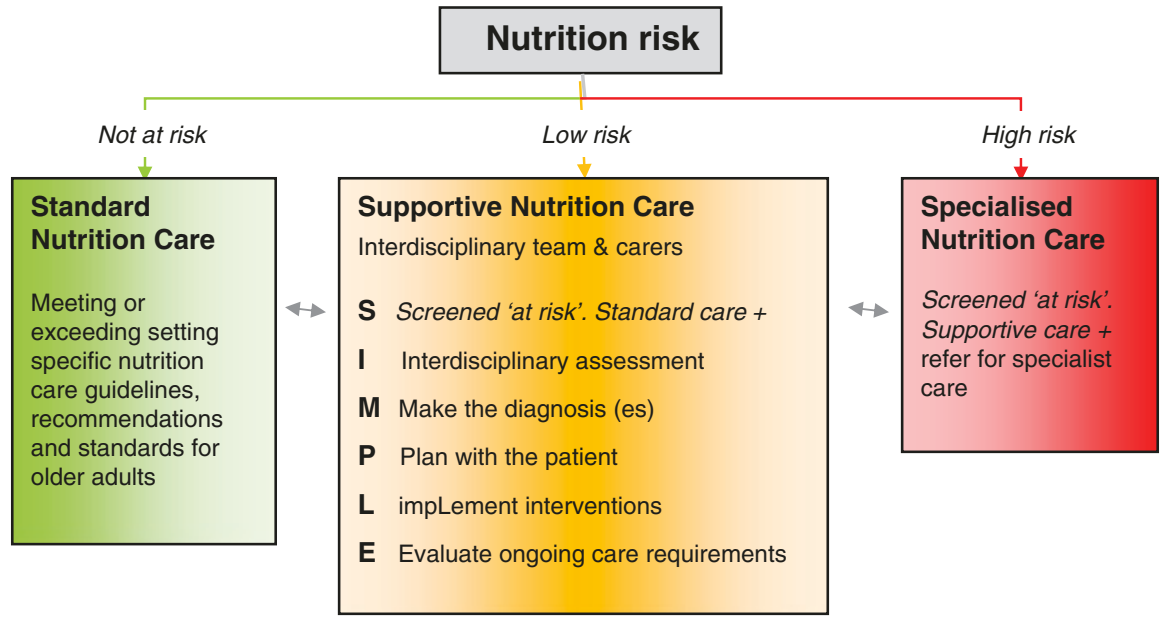

Fig. 1.2 A SIMPLE nutrition care approach. (Source: Adapted to fit from key nutrition care models $[27,43,46-48])$ 


\subsubsection{A SIMPLE Case Example}

An educational case example is now presented to illustrate how the SIMPLE model may be applied across practice settings.

\section{Case Example}

Mary is an 83-year-old female with hip fracture, admitted to a hospital with minimal dietetics services. She lost her husband 4 months ago, lives alone and has no children.

Anthropometry: Height $162 \mathrm{~cm}$, weight $82 \mathrm{~kg}$ and BMI 32; she has lost $10 \mathrm{~kg}$ in the last 6 months secondary to complications after cardiac surgery and sepsis on multiple recent admissions.

Medical history: Type 2 diabetes, high blood pressure, hyperlipidaemia, depressed and excessive alcohol intake.

Pharmacy: Cardiovascular drugs (cholesterol and blood pressure lowering), psychotropic drugs (antidepressant, anti-anxiety and sleeping aid) and oral hypoglycaemic agents for type 2 diabetes.

Day 2 post-op rapport: She has fever and chest infection. She has had hypoactive delirium since admission, and now the medical team is questioning whether she has underlying cognitive impairment and whether she might be drowsy due to overmedication for post-operative pains. She has had poor oral intake since admission. She gets standard hospital diet but without dessert and sweet bread because of her T2DM and obesity. A nurse has noticed that she coughed a couple of times while she was drinking her tea. There is a stage 2 pressure injury on her right heel.

Cases like Mary's are encountered every day by staff working in geriatric care settings. It highlights the complexity of nutritional issues that need to be considered by the interdisciplinary team but also provides an example for SIMPLE supportive care.

\subsubsection{S-Screen for Malnutrition}

Mary will be identified as 'at risk' of malnutrition when she is screened using most internationally applied, validated malnutrition screening tools.

\subsubsection{I-Interdisciplinary Assessment}

Unfortunately, in many settings Mary would not have been screened for malnutrition risk and, even if positively screened, may not have met the clinical prioritisation criteria for specialist nutrition care. In many settings globally, access to timely 
dietitian or medical nutrition specialist care is simply not going to be available for Mary. Whether Mary would meet requirements for 'supportive' versus 'specialised' care will consequently be dependent on setting, but in this case, we suggest supportive, rather than standard care, should be considered as a minimum.

\subsubsection{M-Make the Diagnosis (es)}

Multiple nutrition-related diagnoses are evident, and the evidence-based recommendations for nutrition care are, at best, difficult to align but are more likely to be conflicting. For example, Mary has diabetes and is overweight, and she reports a long-standing low-cholesterol, 'low-sugar' diet; so she is happy about her weight loss. Unfortunately, Mary is also malnourished, in part reflecting restrictive dieting, excessive alcohol intake and poor intake associated with depression and social disconnection. In most settings, this will be the recognised priority in addressing Mary's nutritional diagnosis.

\subsubsection{P-Plan with the Older Adult}

Identifying the priority diagnosis and balancing nutrition co-diagnoses cannot generally be guided by evidence-based algorithms. Instead, clinical judgement and engagement with the older adult, their family, carers and treating teams are necessary in understanding and definition of shared treatment goals. In such cases, some components of nutrition care may be appropriately delivered by the interdisciplinary team, but only if they ask the right questions and work together with the older adult. What are their requirements and priorities? What does the evidence suggest? What is the treatment intent? What does the older adult want? If nutrition care is genuinely complex and likely to benefit from specialist attention, this should be prioritised wherever resources permit.

\subsubsection{L-Implement Interventions}

An evidence-based, multi-modal, interdisciplinary approach that promotes 'nutrition as a medicine', interdisciplinary nutrition care, food-service enhancements, improved nutrition knowledge and awareness and coordination of pre- and postdischarge nutrition care is likely to improve outcomes for older adults like Mary [31].

\subsubsection{E-Evaluate Ongoing Care Requirements}

Ensuring that individual and systems processes for the evaluation of ongoing care requirements are in place is a key component of integrated care. Where possible, engaging the older adult in self-monitoring should be a key priority and supported by post-discharge follow-up of nutrition by a general practitioner.

\subsection{Bringing It All Together: Integrated Nutrition Care Across the Four Pillars of (Ortho) Geriatric Care}

The following chapters of this book are written with older adults like Mary, and all those who care for her, firmly in mind. Chapters are centred around the key pillars of the call to action for orthogeriatric care [49]. These invoke the need to consider 
(1) the core business of primary and secondary prevention strategies, (2) the interdisciplinary management of the acute period and (3) the rehabilitation phase, recognised as continuing for the rest of the older adult's life.

To support these three clinical pillars, a fourth is highlighted-the political pillar of creating national interdisciplinary alliances between relevant mainstream professional associations, to push for the policy change and multi-professional education that is needed if the first three are to gain impetus.

In considering these fundamental pillars of care, each chapter presents an evaluation of the current evidence for best practice, balanced with 'in field' applied understanding regarding how to balance 'best practice' with the realities of routinely confounding, and often conflicting, recommendations, conditions, resources perceptions, biases and team and older adult expectations.

The mantra of this book is that we should avoid applying prescriptive 'must do' algorithms or formulae, but readers will be challenged to consider their own local context and to decide how to prioritise efficient and effective nutrition care that matters to older adults, in the right place, at the right time, by the right healthcare providers. This approach will also support care across settings, whether medical nutrition specialist access, experiences and resources are readily accessible, limited or simply not available.

The purpose of Chap. 2 is to describe the nutritional recommendations for older adults and introduce the need to consider changes in requirements with age and disease. Chapter 3 shares knowledge about terminology and best practice for the nutrition care for older adult. Chapter 4 is about malnutrition prevention in older adults where many factors influence the nutritional intake, wellbeing and quality of life. This will introduce the need to consider acute or chronic diseases, and a reduced dietary intake plays a crucial role in developing malnutrition. A key aim of this chapter is to increase the nutritional-based knowledge of nurses and other healthcare providers to prevent malnutrition. Chapter 5 describes the practical aspects of nutrition support, including nutritional dense food, nutritional supplements and/or when enteral and parenteral nutrition may be used. The ethical aspects of nutrition support are also considered. This chapter also makes the case that perhaps the most critical tool in a dietitian or medical nutrition specialists toolkit is a clinically focussed food-service system.

Chapter 6 describes opportunities for nursing to demonstrate leadership in nutrition care, whether to supporting healthy eating to sustain healthy ageing and prevent and manage malnutrition; endocrine, immune system and organ dysfunction; muscle strength and function; bone health in older adults; or a combination of these. Considerations regarding assessment of hydration status, recommendations and guidelines for hydration, fluid intake and intravenous fluid therapy are provided in Chap. 7. Chapter 8 aims to untangling ageing, malnutrition, frailty, sarcopenia and function; these are different conditions with overlapping characteristics, consequences and interventional opportunities in older adults. These can often be hidden conditions; hence interdisciplinary awareness is needed for optimal identification and management. Chapter 9 aims to introducing bone health in older adult, what happens with ageing and how we diagnose osteoporosis. What we can do from a nutritional and non-nutritional perspective in preventing osteoporosis and supporting those with osteoporosis? 
Many factors influence eating behaviour and nutritional status in older adults. Chapter 10 introduces the need to consider how to increase older adult motivation, factors that support or confound adherence to nutrition care, and reminds readers that eating habits are inseparably linked with people's physical and psychological health and wellbeing. An overarching aim of this chapter is to assist healthcare providers to consider psychological barriers that may lead older adults away from engaging with nutrition care and the importance of motivational interventions to support adherence to nutrition care. This chapter also provides useful insights and direction for further research.

Malnutrition prevention, detection and treatment in older adults benefit from an interdisciplinary approach, regardless of the care setting. The focus of Chap. 11 challenges the reader regarding how to engage older adults and teams in developing and sustaining models of nutrition care with an emphasis on interdisciplinary approaches. Implementation programmes are showcased that demonstrate the rationale and evidence for why and how to engage treating teams to spread and sustain nutrition care improvements across healthcare systems. Education improves interprofessional engagement with nutrition care across pillars. Chapter 12 details underpinnings and pragmatic approaches to education of healthcare providers. This will provide the reader with knowledge and skills to support interprofessional education that embeds evidence-based collaborative nutrition care and improves delivery for older adults. Key models supporting an interdisciplinary approach to nutrition care are covered in Chap. 13. Internationally applicable care pathways are presented that support interdisciplinary care for hospitals and to support integrated care beyond the hospital setting. The challenge of whether acute hospitals are the best environments to resolve malnutrition versus the need for interdisciplinary leadership, champions and resources to support scale and spread of nutrition care across the continuum is a common theme embedded across Chaps. 10-12.

Chapter 14 summarises the current evidence about the role of physical activity, exercise and physical rehabilitation with an emphasis on nutritional aspects. The focus of Chap. 15 is on the link between malnutrition and interventions in preventing and managing pressure injuries. Chapter 16 provides an overview of obesity, and body composition, and importantly targets an increased awareness of the limitations of commonly applied measure of muscle and body fatness such as the BMI. Chapter 17 provides an extension learning chapter to highlight that even detailed assessments that delineate muscle versus fat disregard the different types of fat and how these body fat mass should be considered not as simple energy storage but a complex human organ. The mouth is the first stage of digestion, and understanding oral health and oropharyngeal dysphagia as important factor in malnutrition are described in Chap. 18. Delirium is a common and serious complication in hospitalised older people. Poor nutrition and hydration are both risk factors for, and consequences of, delirium. Chapter 19 discusses the phenomenology of delirium and the role of nurses and other healthcare professionals in recognising, preventing and managing this serious complication. Interaction between food and drugs is a complex subject as prescribed drugs can affect the nutritional uptake of older adults 
and diet and timing of eating can change the efficacy of drugs. Consequently, Chapter 20 provides some detail on common supplementation and drug-food and food-drug interactions.

End-of-life care constitutes an important situation of extreme nutritional vulnerability for older adults. Feeding decisions often provoke wrenching moral and ethical questions for family members regarding whether to continue hand feeding or opt for tube feeding placement. Supporting older adults, and those who care for them, to make informed decision-making at the end of life is the focus on Chap. 21. This chapter provides practical examples that illustrate the unique complexities that should be considered when planning which, if any, medical nutrition therapies (by oral and artificial means) should be considered at the end of life.

\subsection{Summary: Finishing Off with a List of New Questions}

We have made the case that malnutrition is a wicked problem and noted that nutrition care is often provided across highly complex healthcare settings. Consequently, it would be naïve to conclude that malnutrition care in older adults is simple. We have suggested that reliance on specialists may delay or prevent timely, supportive nutrition care. However, we have also observed that timely, appropriate nutritional assessments and interventions are often overlooked or disregarded by 'in situ' interdisciplinary healthcare professionals, despite the high prevalence of nutritionrelated diagnoses across geriatric populations and the potential cost benefits of early identification and treatment $[5,6,27]$.

Successful and sustained nutrition care requires the engagement of older adults, carers and interdisciplinary teams using a knowledge translation approach. This, ideally, should foster tailoring of nutrition care using co-designed approaches. Interventions planned at the individual level should consider a shared decisionmaking approach, including informed consent and goal setting, and establishing monitoring and reassessment processes to identify whether interventions are effective and consistent with older adult goals and healthcare system deliverables [7, 50]. 'Cut and paste' approaches to nutrition care model reforms are less likely to be successful, either initially or sustained and spread [40, 51, 52].

We conclude that multi-modal, co-designed interventions, delivered by diverse healthcare workers, are pivotal to nutrition care of the older adult; these need to be integrated across acute care, rehabilitation and primary/secondary prevention in the community [45, 53-59]. Consequently, to finish this introductory chapter on a pragmatic note, we propose some nutrition-focussed questions that may be asked by nurses or other healthcare workers, regardless of setting (Table 1.2). This is not an exhaustive list but provides a useful place to start. A cross-reference to the relevant chapters in this book is provided, to provide insights into why these questions should be asked and what could be actioned in response to support integrated care for older adults like Mary who are at risk of malnutrition or already malnourished. 
Table 1.2 Some useful nutrition-focussed questions to ask yourself when working with an older adult

\begin{tabular}{|c|c|}
\hline Question & Key sources for further information \\
\hline $\begin{array}{l}\text { What are Mary's nutrition requirements, } \\
\text { needs and preferences? }\end{array}$ & Chapter 2: Nutritional Requirements in Geriatrics \\
\hline $\begin{array}{l}\text { Are Mary's requirements being met? Is } \\
\text { Mary at risk of or already has a nutrition- } \\
\text { related diagnosis or condition? }\end{array}$ & $\begin{array}{l}\text { Chapter 3: Nutritional Assessment, Diagnosis } \\
\text { and Treatment in Geriatrics }\end{array}$ \\
\hline $\begin{array}{l}\text { Could we have prevented Mary from } \\
\text { becoming malnourished? }\end{array}$ & $\begin{array}{l}\text { Chapter 4: Malnutrition Prevention } \\
\text { Chapter 5: Nutrition support in older adults }\end{array}$ \\
\hline $\begin{array}{l}\text { Is it an essential nursing role to support } \\
\text { nutrition care for Mary? }\end{array}$ & $\begin{array}{l}\text { Chapter 6: Supporting nutritional care in older } \\
\text { adults - an essential component of 'best practice' } \\
\text { nursing }\end{array}$ \\
\hline Is Mary appropriately hydrated? & $\begin{array}{l}\text { Chapter 7: Preventing and managing hydration } \\
\text { and dehydration in older people }\end{array}$ \\
\hline $\begin{array}{l}\text { Is Mary malnourished or frail, or is it } \\
\text { something else? }\end{array}$ & $\begin{array}{l}\text { Chapter 8: Untangling Ageing, Malnutrition, } \\
\text { Frailty, Sarcopenia and Function Decline }\end{array}$ \\
\hline $\begin{array}{l}\text { Why did Mary fracture her hip? And could } \\
\text { we have prevented it? }\end{array}$ & $\begin{array}{l}\text { Chapter 9: Bone Health, Fragility and Fractures } \\
\text { Chapter 14: Physical Activity, Exercise, and } \\
\text { Physical Rehabilitation }\end{array}$ \\
\hline How do I engage Mary in her nutrition care? & $\begin{array}{l}\text { Chapter 10: How to Increase Older Adult } \\
\text { Motivation and Adherence to Nutritional Care? } \\
\text { Overcoming Psychological Barriers }\end{array}$ \\
\hline $\begin{array}{l}\text { How do I engage other team members in } \\
\text { nutrition care? }\end{array}$ & $\begin{array}{l}\text { Chapter 11: How to Engage Treating Teams to } \\
\text { Spread and Sustain Nutritional Care }\end{array}$ \\
\hline $\begin{array}{l}\text { How can I improve the nutrition knowledge } \\
\text { of all those who might influence Mary's } \\
\text { nutrition care }\end{array}$ & $\begin{array}{l}\text { Chapter 12: Interdisciplinary Team and } \\
\text { Education of Professionals }\end{array}$ \\
\hline $\begin{array}{l}\text { Who else might help to support nutrition } \\
\text { care for Mary? }\end{array}$ & $\begin{array}{l}\text { Chapter 13: Key opportunities for } \\
\text { multidisciplinary malnutrition care }\end{array}$ \\
\hline $\begin{array}{l}\text { Is it worth the effort of trying to get Mary } \\
\text { out of bed? }\end{array}$ & $\begin{array}{l}\text { Chapter 14: Physical Activity, Exercise, and } \\
\text { Physical Rehabilitation }\end{array}$ \\
\hline $\begin{array}{l}\text { Could we have prevented Mary's pressure } \\
\text { injury? Will nutrition help? }\end{array}$ & $\begin{array}{l}\text { Chapter 15: Pressure Ulcer Prevention and } \\
\text { Management }\end{array}$ \\
\hline $\begin{array}{l}\text { I still don't understand why Mary is } \\
\text { malnourished even though she is obese. } \\
\text { Isn't fat just fat? }\end{array}$ & $\begin{array}{l}\text { Chapter 16: Obesity, Body Composition and BMI } \\
\text { Chapter 17: Fundamentals of Nutritional } \\
\text { Physiology }\end{array}$ \\
\hline Is Mary just coughing or is she aspirating? & $\begin{array}{l}\text { Chapter 18: Nutrition in Oropharyngeal } \\
\text { Dysphagia }\end{array}$ \\
\hline What do I do about the delirium? & Chapter 19: Nutrition and Delirium \\
\hline How are the medicines interacting with the & Chapter 20: Drug-Food and Food-Drug \\
\hline In the end, just how much does food matter? & $\begin{array}{l}\text { Chapter 21: End of Life, Food and Water: Ethical } \\
\text { Standards of Care }\end{array}$ \\
\hline
\end{tabular}




\section{References}

1. World Health Organisation (2020) Malnutrition. https://www.who.int/news-room/q-a-detail/ malnutrition

2. Agarwal E, Miller M, Yaxley A, Isenring E (2013) Malnutrition in the elderly: a narrative review. Maturitas 76(4):296-302

3. Elia M, Stratton RJ (2011) Considerations for screening tool selection and role of predictive and concurrent validity. Curr Opin Clin Nutr Metab Care 14(5):425-433

4. Bell JJ, Bauer JD, Capra S, Pulle RC (2014) Concurrent and predictive evaluation of malnutrition diagnostic measures in hip fracture inpatients: a diagnostic accuracy study. Eur J Clin Nutr 68(3):358-362

5. Bell JJ, Bauer JD, Capra S, Pulle RC (2014) Quick and easy is not without cost: implications of poorly performing nutrition screening tools in hip fracture. J Am Geriatr Soc 62(2):237-243

6. Bell JJ, Bauer J, Capra S, Pulle CR (2013) Barriers to nutritional intake in patients with acute hip fracture: time to treat malnutrition as a disease and food as a medicine? Can J Physiol Pharmacol 91(6):489-495

7. Bell JJ, Geirsdóttir ÓG, Hertz K, Santy-Tomlinson J, Skúladóttir SS, Eleuteri S et al (2021) Nutritional care of the older patient with fragility fracture: opportunities for systematised, interdisciplinary approaches across acute care, rehabilitation and secondary prevention settings. In: Falaschi P, Marsh D (eds) Orthogeriatrics: the management of older patients with fragility fractures. Springer International, Cham, pp 311-329

8. Burton-Shepherd A (2013) Preventing malnutrition in home-dwelling elderly individuals. Br J Community Nurs (Suppl Nutrition):S25-S31

9. Legrain S, Tubach F, Bonnet-Zamponi D, Lemaire A, Aquino JP, Paillaud E et al (2011) A new multimodal geriatric discharge-planning intervention to prevent emergency visits and rehospitalizations of older adults: the optimization of medication in AGEd multicenter randomized controlled trial. J Am Geriatr Soc 59(11):2017-2028

10. Bell CL, Tamura BK, Masaki KH, Amella EJ (2013) Prevalence and measures of nutritional compromise among nursing home patients: weight loss, low body mass index, malnutrition, and feeding dependency, a systematic review of the literature. J Am Med Dir Assoc 14(2):94-100

11. Adebusoye LA, Ajayi IO, Dairo MD, Ogunniyi AO (2012) Nutritional status of older persons presenting in a primary care clinic in Nigeria. J Nutr Gerontol Geriatr 31(1):71-85

12. Aliabadi M, Kimiagar M, Ghayour-Mobarhan M, Shakeri MT, Nematy M, Ilaty AA et al (2008) Prevalence of malnutrition in free living elderly people in Iran: a cross-sectional study. Asia Pac J Clin Nutr 17(2):285-289

13. Kabir ZN, Ferdous T, Cederholm T, Khanam MA, Streatfied K, Wahlin A (2006) Mini nutritional assessment of rural elderly people in Bangladesh: the impact of demographic, socioeconomic and health factors. Public Health Nutr 9(8):968-974

14. Volkert D, Beck AM, Cederholm T, Cereda E, Cruz-Jentoft A, Goisser S et al (2019) Management of malnutrition in older patients-current approaches, evidence and open questions. J Clin Med 8(7)

15. Cereda E, Pedrolli C, Klersy C, Bonardi C, Quarleri L, Cappello S et al (2016) Nutritional status in older persons according to healthcare setting: a systematic review and meta-analysis of prevalence data using MNA(®). Clin Nutr 35(6):1282-1290 
16. Lacau St Guily J, Bouvard É, Raynard B, Goldwasser F, Maget B, Prevost A et al (2018) NutriCancer: a French observational multicentre cross-sectional study of malnutrition in elderly patients with cancer. J Geriatr Oncol 9(1):74-80

17. Cereda E, Veronese N, Caccialanza R (2018) The final word on nutritional screening and assessment in older persons. Curr Opin Clin Nutr Metab Care 21(1):24-29

18. Bell JJ, Pulle RC, Lee HB, Ferrier R, Crouch A, Whitehouse SL (2021) Diagnosis of overweight or obese malnutrition spells DOOM for hip fracture patients; a prospective audit. Clin Nutr 40(4):1905-1910

19. Dent E, Visvanathan R, Piantadosi C, Chapman I (2012) Nutritional screening tools as predictors of mortality, functional decline, and move to higher level care in older people: a systematic review. J Nutr Gerontol Geriatr 31(2):97-145

20. Rasheed S, Woods RT (2013) Malnutrition and quality of life in older people: a systematic review and meta-analysis. Ageing Res Rev 12(2):561-566

21. Al Snih S, Raji MA, Markides KS, Ottenbacher KJ, Goodwin JS (2005) Weight change and lower body disability in older Mexican Americans. J Am Geriatr Soc 53(10):1730-1737

22. Arnold AM, Newman AB, Cushman M, Ding J, Kritchevsky S (2010) Body weight dynamics and their association with physical function and mortality in older adults: the cardiovascular health study. J Gerontol A Biol Sci Med Sci 65(1):63-70

23. Ritchie CS, Locher JL, Roth DL, McVie T, Sawyer P, Allman R (2008) Unintentional weight loss predicts decline in activities of daily living function and life-space mobility over 4 years among community-dwelling older adults. J Gerontol A Biol Sci Med Sci 63(1):67-75

24. Chang M, Geirsdottir OG, Launer LJ, Gudnasson V, Visser M, Gunnarsdottir I (2020) A poor appetite or ability to eat and its association with physical function amongst communitydwelling older adults: age, gene/environment susceptibility-Reykjavik study. Eur J Ageing

25. Lackoff AS, Hickling D, Collins PF, Stevenson KJ, Nowicki TA, Bell JJ (2020) The association of malnutrition with falls and harm from falls in hospital inpatients: findings from a 5-year observational study. J Clin Nurs 29(3-4):429-436

26. Morley JE (2011) Assessment of malnutrition in older persons: a focus on the mini nutritional assessment. J Nutr Health Aging 15(2):87-90

27. Bell JJ, Young A, Hill J, Banks M, Comans T, Barnes R et al (2018) Rationale and developmental methodology for the SIMPLE approach: a systematised, interdisciplinary malnutrition pathway for impLementation and evaluation in hospitals. Nutr Diet 75(2):226-234

28. OECD (2019) Pensions at a Glance 2019

29. Division DoEaSA-P (2019) World population prospects 2019—highlights. United Nations, Affairs DoEaS, New York

30. Lee RJ, Collins PF, Elmas K, Bell JJ (2019) Restrictive diets in older malnourished cardiac inpatients: a cross-sectional study. Nutr Diet 78(2):121-127

31. Bell JJ, Bauer JD, Capra S, Pulle RC (2014) Multidisciplinary, multi-modal nutritional care in acute hip fracture inpatients - results of a pragmatic intervention. Clin Nutr 33(6):1101-1107

32. Young AM (2015) Solving the wicked problem of hospital malnutrition. Nutr Diet 72(3):200-204

33. Rittel HWJ, Webber MM (1973) Dilemmas in a general theory of planning. Pol Sci 4(2):155-169

34. Jeejeebhoy KN, Keller H, Gramlich L, Allard JP, Laporte M, Duerksen DR et al (2015) Nutritional assessment: comparison of clinical assessment and objective variables for the prediction of length of hospital stay and readmission. Am J Clin Nutr 101(5):956-965

35. Curtis LJ, Bernier P, Jeejeebhoy K, Allard J, Duerksen D, Gramlich L et al (2017) Costs of hospital malnutrition. Clin Nutr 36(5):1391-1396

36. Marques-Vidal P, Khalatbari-Soltani S, Sahli S, Coti Bertrand P, Pralong F, Waeber G (2018) Undernutrition is associated with increased financial losses in hospitals. Clin Nutr 37(2):681-686

37. Welsh TJ, Gordon AL, Gladman JR (2014) Comprehensive geriatric assessment-a guide for the non-specialist. Int J Clin Pract 68(3):290-293 
38. Pioli G, Davoli M, Pellicciotti F, Pignedoli P, Ferrari A (2011) Comprehensive care. Eur J Phys Rehabil Med 47(2):265-279

39. Holmesland A-L, Seikkula J, Nilsen O, Hopfenbeck M, Erik AT (2010) Open dialogues in social networks: professional identity and transdisciplinary collaboration. Int J Integr Care 10:e53

40. Bell JJ, Rossi T, Bauer JD, Capra S (2014) Developing and evaluating interventions that are applicable and relevant to inpatients and those who care for them; a multiphase, pragmatic action research approach. BMC Med Res Methodol 14:98

41. Van Bewer V (2017) Transdisciplinarity in health care: a concept analysis. Nurs Forum 52(4):339-347

42. Rosenfield PL (1992) The potential of transdisciplinary research for sustaining and extending linkages between the health and social sciences. Soc Sci Med 35(11):1343-1357

43. Elia M (2003) In: Nutrition BAfPaE (ed) Screening for malnutrition: a multidisciplinary responsibility. Development and use of the malnutrition universal screening tool (MUST) for adults. BAPEN, Redditch

44. Keller H, Laur C, Atkins M, Bernier P, Butterworth D, Davidson B et al (2018) Update on the integrated nutrition pathway for acute care (INPAC): post implementation tailoring and toolkit to support practice improvements. Nutr J 17(1):2

45. Jensen GL, Compher C, Sullivan DH, Mullin GE (2013) Recognizing malnutrition in adults: definitions and characteristics, screening, assessment, and team approach. J Parenter Enteral Nutr 37(6):802-807

46. Keller H, Laur C, Valaitis R, Bell J, McNicholl T, Ray S et al (2017) More-2-eat: evaluation protocol of a multi-site implementation of the integrated nutrition pathway for acute care. BMC Nutr 3(1):13

47. Writing Group of the Nutrition Care Process/Standardized Language Committee (2008) Nutrition care process and model part I: the 2008 update. J Am Diet Assoc 108(7):1113-1117

48. Isenring EA, Bauer JD, Banks M, Gaskill D (2009) The malnutrition screening tool is a useful tool for identifying malnutrition risk in residential aged care. J Hum Nutr Diet 22(6):545-550

49. Dreinhöfer KE, Mitchell PJ, Bégué T, Cooper C, Costa ML, Falaschi P et al (2018) A global call to action to improve the care of people with fragility fractures. Injury 49(8):1393-1397

50. Jensen GL, Mirtallo J, Compher C, Dhaliwal R, Forbes A, Grijalba RF et al (2010) Adult starvation and disease-related malnutrition: a proposal for etiology-based diagnosis in the clinical practice setting from the international consensus guideline committee. J Parenter Enteral Nutr 34(2):156-159

51. Laur C, Bell J, Valaitis R, Ray S, Keller H (2018) The Sustain and Spread Framework: strategies for sustaining and spreading nutrition care improvements in acute care based on thematic analysis from the More-2-Eat study (Report). BMC Health Serv Res 18(1):930

52. Laur C, Valaitis R, Bell J, Keller H (2017) Changing nutrition care practices in hospital: a thematic analysis of hospital staff perspectives. BMC Health Serv Res 17(1):498

53. Keller H, Koechl JM, Laur C, Chen H, Curtis L, Dubin JA et al (2021) More-2-eat implementation demonstrates that screening, assessment and treatment of malnourished patients can be spread and sustained in acute care; a multi-site, pretest post-test time series study. Clin Nutr 40(4):2100-2108

54. Keller HH, Valaitis R, Laur CV, McNicholl T, Xu Y, Dubin JA et al (2019) Multi-site implementation of nutrition screening and diagnosis in medical care units: success of the More-2-eat project. Clin Nutr 38(2):897-905

55. Volkert D, Beck AM, Cederholm T, Cruz-Jentoft A, Goisser S, Hooper L et al (2019) ESPEN guideline on clinical nutrition and hydration in geriatrics. Clin Nutr 38(1):10-47

56. National Institute for Health and Clinical Excellence (NICE) (2006) Nutrition support in adults: oral nutrition support, enteral tube feeding and parenteral nutrition (clinical guideline 32)

57. Watterson C, Fraser A, Banks M (2009) Evidence based practise guidelines for the nutritional management of malnutrition in adult patients across the continuum of care. Nutr Diet 66:S1-S34 
58. NICE (2012) NICE quality standard 24: quality standard for nutrition support in adults. NICE, London

59. Tappenden KA, Quatrara B, Parkhurst ML, Malone AM, Fanjiang G, Ziegler TR (2013) Critical role of nutrition in improving quality of care: an interdisciplinary call to action to address adult hospital malnutrition. J Parenter Enteral Nutr 37(4):482-497

\section{Recommended Reading}

Bell JJ et al (2018) Rationale and developmental methodology for the SIMPLE approach: a systematised, interdisciplinary malnutrition pathway for impLementation and evaluation in hospitals. Nutr Diet 75(2):226-234

Bell JJ et al (2021) Nutritional care of the older patient with fragility fracture: opportunities for systematised, interdisciplinary approaches across acute care, rehabilitation and secondary prevention settings. In: Falaschi P, Marsh D (eds) Orthogeriatrics. Practical issues in geriatrics. Springer, Cham. https://doi.org/10.1007/978-3-030-48126-1_18

Bell JJ, Young AM, Hill JM, Banks MD, Comans TA, Barnes R, Keller HH (2021) Systematised, interdisciplinary malnutrition program for impLementation and evaluation delivers improved hospital nutrition care processes and patient reported experiences - an implementation study. Nutr Diet. Epub ahead of print. https://doi.org/10.1111/1747-0080.12663

Volkert D et al (2019) ESPEN guideline on clinical nutrition and hydration in geriatrics. Clin Nutr 38(1):10-47. https://doi.org/10.1016/j.clnu.2018.05.024

World Health Organization (2017) ICOPE guidelines-World Health Organization. https://www. who.int/ageing/health-systems/icope/evidence-centre/ICOPE-evidence-profile-malnutrition. pdf?ua=1

Open Access This chapter is licensed under the terms of the Creative Commons Attribution 4.0 International License (http://creativecommons.org/licenses/by/4.0/), which permits use, sharing, adaptation, distribution and reproduction in any medium or format, as long as you give appropriate credit to the original author(s) and the source, provide a link to the Creative Commons license and indicate if changes were made.

The images or other third party material in this chapter are included in the chapter's Creative Commons license, unless indicated otherwise in a credit line to the material. If material is not included in the chapter's Creative Commons license and your intended use is not permitted by statutory regulation or exceeds the permitted use, you will need to obtain permission directly from the copyright holder.

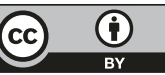

